positive confidence. The consequences are farreaching.

If the line of ideas, the general direction only of which I have space to indicate, is to lead beyond a mere theoretical construction and make a solid contribution to knowledge, the interest and effort of philosophers, logicians, mathematicians, psychologists and economists will be needed for the intensive exploration of a territory the outlines of which were so brilliantly mapped by the seven contributors to the symposium at Liverpool.

So much for the distinctive features of the individual contributions. The following concepts and themes recurred in a number of the papers, and these suggest the movement of thought from which new developments in expectation theory may emerge.

Dissatisfaction with the frequency theory of probability. Decisions have often to be made concerning novel and unrepeated ventures. To these any frequency measure of probability is inapplicable; but even where it is theoretically applicable, there is a growing disbelief in the facile assumption that business decisions are based upon it.

The realization of the need for greater psychological realism on the part of economists. In a world in which the irrationality of man is everywhere manifest, it does seem somewhat naive to assume that the business-man, of all people, is gifted with some unique degree of rationality which would give a mathematical sanction to his daily business decisions. It should, however, be pointed out that the word 'rational' itself demands some scrutiny. It is used to mean either 'effective' or 'ratiocinative'. There is a sort of practical rationality, or expertize, which depends upon vears of experience rather than upon ratiocination. It is this which gives some measure of cogency to the degree of belief which the expert accords to the particular proposition.

The magnitude of the methodological problem. This is multifarious, and includes the relations between the social and the individual, conception and action, continuity and discontinuity, single and multiple causation, and a host of other relations.

The bearing of causative contexts and conceptual frameworks. The isolated business decision is probably a fiction. Decision arises out of the conceptual framework of the individual, and takes place within his socio-economic context.

The role of the conceptual model in theory-making. Theory attempts to simplify and clarify the welter of facts. It can do this only by setting up relatively self-contained abstract models; such a model, if it is to survive, must possess three features : internal consistency, as determined by logical analysis; validity, as determined by empirical tests; and power, as determined by its utility in both clarification and prediction.

The problem of quantification. This is an aspect of the validity problem, for in comparing empirical data with predicted outcomes there is a direct comparison of quantities. The theory of measurement is far from complete; even the physicists have their problems of metrology. Psychometrics and econometrics present problems of even greater complexity, but these are a challenge rather than a ground for pessimism.

A growing need for an adequate calculus of discrete quantities (as against the calculus of the arithmetical continuum). This may not be difficult for the pure mathematicians, but the users of mathematics would need to acquire new habits of thought, as well as new modes of calculation. The landscape model of Shackle's function in the accompanying illustration would have to make way for a model of steps and movable platforms.

G. P. Meredith

\section{PROTON SYNCHROTRON OF THE UNIVERSITY OF BIRMINGHAM}

$T$ HE proton synchrotron in the Physics Department of the University of Birmingham is now able to accelerate particles to an energy of $1,000 \mathrm{MeV}$.; it first operated at full energy on July 16. A greater energy than this is known to have been reached artificially only in the United States, where the Brookhaven 'Cosmotron' gives protons of an energy of $2,300 \mathrm{MeV}$. These two machines, together with a rather larger proton synchrotron approaching completion at Berkeley, California, are designed to provide experimental facilities for nuclear physics in an energy range above that which is economic for synchro-cyclotrons. Future proton synchrotrons, planned to incorporate the new strong focusing principle, will probably extend the energy scale considerably further.

The Birmingham synchrotron has been developed from the original proposals of Oliphant, Gooden and $\mathrm{Hide}^{2}$, whose aim to reach a proton energy of about $1,000 \mathrm{MeV}$. was, just after the Second World War, ambitious but not unreasonable. Detailed design began in 1946 with the aid of a grant from the Nuffield Foundation, and construction started in 1947. The project was under the guidance of Prof. M. L. Oliphant until he left the laboratory in 1950 , and, since then, responsibility for the development and testing of the machine has been in the hands of the present head of the Department, Prof. P. B. Moon. The undertaking has been financed mainly by the Department of Scientific and Industrial Research, without the support of which the project could scarcely have been undertaken by a university department. Several large and important parts of the equipment, such as the motor-generator, vacuum sections and high-tension generator, were supplied by outside firms; but the main technical responsibility has been undertaken throughout by the Department of Physics, and much of the actual construction was provided by the departmental workshops. The very considerable technical effort necessary has been supplied over six years by a large number of physicists and assistants, many of whom are no longer in the laboratory to witness the successful outcome of their work.

The first notable feature of the Birmingham synchrotron is its size. This is not shown to advantage in the accompanying photograph, since the machine had to be built within the fairly small space available in the Nuffield Research Laboratory, which was designed for (and still houses) the University 60-in. cyclotron $^{3}$. The illustration gives a general view of the magnet (810 tons), which is built of C-shaped steel laminations $\frac{1}{2}$ in. thick, arranged in a circle with the annular gap outwards. The diameter of the mean horizontal orbit in which the protons circulate is $900 \mathrm{~cm}$., and the magnetic field necessary to keep a proton of an energy of $1,000 \mathrm{MeV}$. moving in an orbit of this size is 12,500 gauss. Power for the magnet is supplied by a motor-generator set developing 


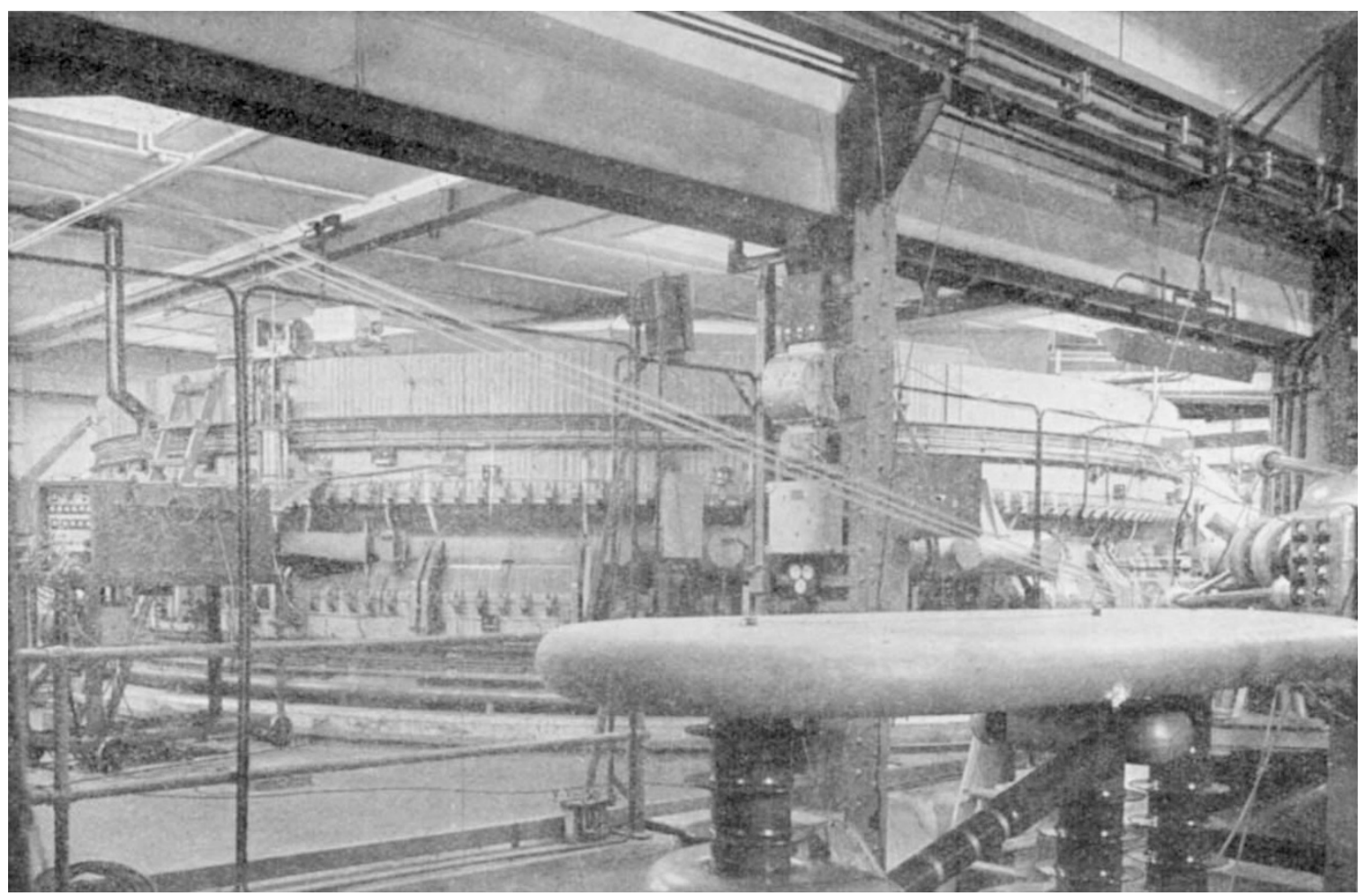

General view of the proton synchrotron of the University of Birmingham, showing magnet, vacuum system, radio-frequency power amplifler and injection apparatus

$1,100 \mathrm{~V}$. which is connected to the air-cooled coils of the magnet at the beginning of the magnetic cycle. The magnet has an inductance of $0 \cdot 1 \mathrm{H}$. and a resistance of $0.01 \mathrm{ohm}$, and a peak current of 12,500 amp. (corresponding to a field of 12,500 gauss in the magnet gap) builds up in the coils in 1 sec. The field excitation of the generator is reversed to limit the peak current and to reduce the current quickly to zero ; when the current has passed its peak, most of the energy stored in the magnet feeds back into the motor generator, which has on its shaft a 36-ton flywheel for energy storage. The magnetic field-cycle repeats every $10 \mathrm{sec}$.

The magnet gap is $21 \mathrm{~cm}$. high and contains a sectionalized porcelain vacuum tube of internal dimensions $10 \mathrm{~cm}$. by $36 \mathrm{~cm}$. ; a pressure of $8 \times$ $10^{-7} \mathrm{~mm}$. is maintained by five diffusion pumps each with a speed of $2,000 \mathrm{l} / \mathrm{sec}$. through a water-cooled baffle. A pulse of protons is shot tangentially into the vacuum system from a Cockcroft-Walton hightension generator just after the magnetic field begins to rise. The injection energy is $460 \mathrm{keV}$., and the protons begin to move in a magnetic field which for this energy gives their path a radius"of about $450 \mathrm{~cm}$. On their way around the vacuum system the particles pass through an accelerating electrode ('cee') to which a radio-frequency voltage is applied; for each revolution the proton energy may be thus increased on the average by about $200 \mathrm{eV}$. This energy increment is just that required to maintain the particles in the mean orbit as the magnetic field rises. There must, of course, be synchronism between the applied radio-frequency voltage and the circulating protons, and as the particles speed up the applied frequency is increased. The frequency-range necessary for the acceleration period of 1 sec. is $330 \mathrm{kc} . / \mathrm{s}$. to $9 \cdot 3 \mathrm{Mc} . / \mathrm{s}$., and during this time the protons make about $5 \times 10^{\theta}$ revolutions in or near the mean stable orbit. The necessary radio-frequency voltage on the accelerating electrode is achieved over a $30 / 1$ frequency range by roughly tuning the 'cee' capacitance. This is done by a mechanically variable inductance driven in accordance with the known frequency-time variation. The form of the frequency-time law was found from precise measurements of the rate of rise of magnetic field which has been found satisfactorily reproducible. The radio-frequency is generated as a beat between a fixed oscillator and a variable oscillator the frequency of which is governed by a mechanically driven condenser shaped to provide the correct timevariation. Further details of the whole equipment were given in an earlier article ${ }^{4}$.

In preliminary tests of the synchrotron, beams of particles were observed to strike current collection and scintillation probes inserted at various points in the vacuum tube. For testing over the full range of energy, a convenient form of beam indication is the signal induced on an insulated plate at the bottom of the vacuum system by the bunched beam circulating near the median plane. From the size of this signal, it is estimated that the fully accelerated pulses contain about $10^{8}$ protons. At the conclusion of the acceleration, the beam may be made to move either to the inside or to the outside wall of the vacuum tube; provision is being made for the insertion of suitable targets. Scattered protons have been observed outside the vacuum system, and tracks of $\pi$-mesons have been seen in nuclear emulsions exposed near by.

In the present early stages of operation of the synchrotron, effort is concentrated mainly on im. proving the performance and on measuring radiation 
levels. This is necessary for the proper design of shielding which will protect those working near the machine and also allow access to the various beams of radiation from targets. A detailed experimental programme is being prepared, and it is hoped that this synchrotron, which provides $\pi$-mesons of energies up to at least $700 \mathrm{MeV}$., will add significantly to existing information on the nuclear interactions of high-energy particles. It is clear that the accumulation of events of interest in nuclear emulsions and cloud chambers is likely to be rapid.

${ }^{1}$ Rev. Sci. Instr. (the September 1953 issue is devoted to a description of the Brookhaven cosmotron).

oliphant, M. L., Gooden, J. S., and Hide, G. S., Proc. Phys. Soc, 59 , 666 (1947).

${ }^{3}$ Nature, 169, 476 (1952).

4 Hibbard, L. U., Nucleonics, 7, No. 4, 30 (1950); see also The Engineer, 195, 271 and 305 (1953).

\section{OBITUARIES}

\section{Prof. A. F. Holleman}

Arnold Frederik Holleman died on August 11, and so passed the doyen of Dutch chemists and one who held a special place in the hearts of his countrymen, not only for what he had done for the cause of science, and of organic chemistry in particular, in Holland, but also as one of the band of famous scientists who succeeded in bringing the universities of Holland into the very forefront of scientific progress.

During his long life of almost ninety-four years, Holleman formed a connecting link between the earlier period of organic chemistry and modern developments. He was born at Oisterwijk in North Brabant on August 28, 1859, and received his early chemical education from Dr. Lamers, a pupil of Kekulé. He proceeded in 1879 to Leyden, where he studied under the two famous teachers, Franchimont and van Bemmelen, and also had instruction from van Romburgh, Bakhuis Roozeboom and Lobry de Bruyn. Then followed a period under Bunsen at Heidelberg and one in von Baeyer's laboratory at Munich, where he was contemporary with Bamberger, Claisen, Nef and Friedlander. In 1887 he returned to Holland to work with van't Hoff at Amsterdam, where he also met Eijkman. Here he started his career as a teacher; he became professor at Groningen in 1893, and a little later he succeeded Lobry de Bruyn at Amsterdam, where he remained until he retired in 1924 at the age of sixty-five.

The effect of Holleman's lifelong friendship with van't Hoff and his contacts with Eijkman and Bakhuis Roozeboom is to be seen in the direction his researches took at Groningen and Amsterdam. As a student of the Leyden school, he was interested in the chemistry of substitution in aromatic compounds, and his thesis for his doctorate (1887) dealt with "Researches on the so-called $\beta$-Nitro-cymene"; his fame, however, rests on the application of exact physico-chemical methods to the quantitative study of the problem. His researches enabled him in 1910 to publish his famous book "Die Einführung von Substituenten in den Benzolkern", truly the basis on which the English school later built the electronic theory. He was still stressing the importance of the quantitative aspect of the subject in probably the last of his papers, published in 1947.

After his retirement, Holleman lived in Bloemendaal, but still devoted himself to science, as secretary to the Hollandsche Maatschappij der Wetenschappen, Haarlem, and on various committees of the Dutch Chemical Society, which obtained its Royal title a few days before his death, and in which he was particularly interested.

No notice would be complete without reference to Holleman's fame as a teacher. Anyone who studied organic chemistry at a Dutch university could 'feel' it, and it was also a reason for the success of his text-book, which passed through sixteen editions between 1896 and 1951 (he supervised the whole of the manuscript of a recent English translation) and was translated into many languages. S. CoFFEY

WE regret to announce the following deaths :

Mr. R. H. Burne, F.R.S., sometime physiological curator of the Hunterian Museum, Royal College of Surgeons, on October 9, aged eighty-five.

Mr. James Fairgrieve, formerly reader in education with special reference to geography in the Institute of Education, University of London, on October 8, aged eighty-three.

\section{NEWS and VIEWS}

Aerodynamics at the National Physical Laboratory: Mr. A. Fage, C.B.E., F.R.S.

Mr. A. FAGE, who retired from the post of superintendent of the Aerodynamics Division of the National Physical Laboratory last summer, is one of the pioneers of aeronautical research. He went to the Laboratory in 1912, after an education at the Portsmouth Dockyard Schools and the Royal College of Science, London, and joined the small group of workers who were beginning to establish an aeronautical section at the Laboratory under the guidance of the then Dr. Stanton and Mr. Bairstow. His early work ranged over the whole field of aerodynamics as it then existed; but he made a special study of the characteristics of airscrews and laid the foundations of airscrew theory. He wrote two books at this time, on airscrews and on the aeroplane, as a guide to designers. About 1920, Mr. Fage began to study the problems of the boundary layer and of turbulent airflow which have been his main work and have brought him international fame and the fellowship of the Royal Society (1942). He was the first to measure, by the use of Stanton's surface Pitot tube, the distribution of skin friction along the chord of an aerofoil, and to show in detail the nature of the transition from laminar to turbulent flow. His work on the effects of surface imperfections on skin friction did much to emphasize the great importance of smooth and accurately shaped surfaces for the attainment of the lowest possible drag.

Mr. Fage was a brilliant experimentalist but had a sufficient knowledge of the underlying theory to enable him to interpret Iucidly the results of his experiments. Many of his experimental researches show an almost uncanny skill, and also a great degree of patience, in attacking new and difficult problems. Incidentally, he made some of the first experiments on laminar flow aerofoils. He was appointed superintendent of the Aerodynamics Division at Teddington in 1946 and since then has devoted much of his time 